This item was submitted to Loughborough's Research Repository by the author.

Items in Figshare are protected by copyright, with all rights reserved, unless otherwise indicated.

\title{
Masculinity, age and rapport in qualitative research
}

PLEASE CITE THE PUBLISHED VERSION

http://dx.doi.org/10.1108/S1042-319220160000014014

\section{PUBLISHER}

Emerald

\section{VERSION}

AM (Accepted Manuscript)

\section{PUBLISHER STATEMENT}

This work is made available according to the conditions of the Creative Commons Attribution-NonCommercialNoDerivatives 4.0 International (CC BY-NC-ND 4.0) licence. Full details of this licence are available at: https://creativecommons.org/licenses/by-nc-nd/4.0/

\section{LICENCE}

CC BY-NC-ND 4.0

\section{REPOSITORY RECORD}

Thurnell-Read, Thomas P.. 2019. “Masculinity, Age and Rapport in Qualitative Research”. figshare. https://hdl.handle.net/2134/24519. 
'Masculinity, Age and Rapport In Qualitative Research'

Thurnell-Read, T. 2016. 'Masculinity, Age and Rapport In Qualitative Research', in M. Ward (ed), Gender, Power and Subjectivity: Reflections on Research

Relationships in the Field. Bingley: Emerald (Studies in Qualitative Methods series).

ISBN 9781-78635-026-8

Dr Thomas Thurnell-Read

Department of Social Sciences

Loughborough University

Loughborough

LE11 3TU, UK

Email: t.thurnell-read@lboro.ac.uk 


\title{
Masculinity, Age and Rapport in Qualitative Research
}

\author{
Thomas Thurnell-Read \\ Coventry University
}

\begin{abstract}
Purpose To reflect on the central role of gender and age in qualitative research practice, particularly in regard to how the gender and age of the researcher influence fieldwork interactions.

Design/methodologylapproach A reflection of three separate qualitative research undertakings, all of which made use of interviews and participant-observation fieldwork.

Findings Gender and age intersections of both the researcher and research subjects influence fieldwork interactions both in terms of discursive and embodied interactions. Reflections on past research involve considering the relative changing subject position of the researcher in terms of masculinity, youth and social status. Rapport is established in the field through talk and interaction that can involve the performance of knowledge and gender. The researcher's embodied feeling of 'fitting in' during fieldwork therefor draw on gender, age and ethnicity specific privilege.

Originality/value Unlike many acts of researcher reflexivity which reflect on a single research project, this chapter recalls experiences of fieldwork during three separate research undertakings. It adds to debates about methodological issues of doing research into men and masculinities by exploring how such is intersected by the age of both the researcher and researcher participants.
\end{abstract}

Keywords: Age, Embodiment, Knowledge, Masculinity, Rapport, Reflexivity

Several weeks into what was my first attempt at undertaking qualitative social research, I had a 'breakthrough' moment. It came during an undergraduate project on masculinity and occupational identity in a local fire station and from which my first ever academic publication would emerge (Thurnell-Read and Parker, 2008). Having already made a number of research visits to the local fire station I had begun to get to know my research participants, the 16 male members of Green Watch, who now seemed used to me being around and no longer mistook me for being one of the 'work experience lads' also making occasional appearances in the yard, offices and training rooms of the station. Worryingly, however, I felt I had yet to achieve the 'rapport' with my participants that our course text books had told us was so important 
in a study of this kind (Hammersley and Atkinson, 2007). I still felt nervous that my presence in this place of work normally out of bounds to the public would be interpreted as intrusive. Then I missed a scheduled 'fieldwork' visit in favour of a drinking session at a house party thrown by some fellow students. On returning to the station the following week it was to my surprise that members of Green Watch had noted my absence and, once I sheepishly admitted the reason for my nonappearance, expressed both praise ('good lad') and jealousy ('lucky sod, wish I was young, free and single again'). From that point on, I noted the more relaxed way in which participants conversed with me.

While my main concern at the time was making a success of the research project in order to gain a good grade in the final project write up due that September, my experience of fieldwork was bound up with my own feelings of 'fitting in', or not, in what felt a very adult and very masculine environment (See also Parker this volume). At the time of my 'breakthrough', I was merely happy that my participants seemed to be more relaxed and that the regular notes and 'jottings' in my field diary began to feel more candid, more lived in, and 'thicker' (Geertz, 1973). My errant behaviour in prioritising a session of socialising with fellow students over my commitments to immersing myself in my research field were perceived as appropriate, and in indeed enviable, behaviour for a young man in his early twenties and seemed to achieve some degree of change in my status amongst my participants. I had not consciously played up to this presentation of youthful masculine bravado, and only quite some time later did I begin to realise how much this experience of fieldwork relations was mediated by the age, gender and social class position of myself and of those whose lives I was attempting to learn about through my research. Looking back as an established academic, it is evident that both my gender and my age to a considerable degree influenced my choice of research topic, my ability to access that field and my relationships with participants during my period of participant observation. What worked for me as a young male researcher might not have done so for a female researcher (Schwalbe and Wolkomir, 2001; Leontowitch, 2012; and Tarrant this volume). 
This chapter explores these issues by reflecting on the relationship of gender and age with fieldwork experiences and practice. It therefore explores what Amanda Coffey (1998: 1) has referred to as 'the personal, emotional and identity dimensions of undertaking prolonged fieldwork' and offers reflections on how my identity as an individual and as a male researcher shaped my research of other men. In this chapter I make an intentionally loose review of my own experiences of conducting participatory qualitative research by reflecting on such experiences from across several research projects. It is an act of reflexivity which, as Pillow (2003: 176) suggests, is now widely accepted as a necessary element of good fieldwork practice and involves an 'increased attention to researcher subjectivity in the research process - a focus on how does who I am, who I have been, who I think I am, and how I feel affect data collection and analysis'. Thus, studies of the fire fighters (Thurnell-Read and Parker, 2008), of premarital stag tour celebrations in Eastern Europe (Thurnell-Read, 2011a; 2012) and of 'Real Ale' brewers and enthusiasts (Thurnell-Read, 2014; 2015) have all both directly and indirectly sought insights relating to the social construction of masculinity and the salience of gender as a constituent facet of the work and leisure lives of my participants. They have also been in each case a chance for personal reflection both on my own gendered identity and upon my own development as a researcher and academic. Further still, the changing ages of my participants in each project have led me to reflect on the importance of the intersection of age with masculinity. In this light, I view the research encounter as one where both researcher and researched might be seen as 'doing gender' (West and Zimmerman, 1987) or 'gender displays' (Schrock and Schwalbe 2009) as well as performing a number of other roles relating to positions of relative power and authority. Specifically, my own age and that of my research participants appears to have influenced, to a great extent, the form and nature of social relationships and interactions experiences in the research field.

The following two sections first review some key debates as to methodological issues relating to conducting qualitative research into men and masculinity and then outline in more detail the nature of the three qualitative research studies I will reflect on during the chapter. This is then in turn explored in relation to related themes of how the rapport established with research participants during fieldwork is influenced by the gendered performance of knowledge and 'know-how' and similarities and 
differences framed by age and generational. A final analysis section then explores how rapport and fieldwork relations are also embodied and 'felt' and, further, that this feeling of 'fitting in' is evidently facilitated by gender, age and ethnicity based privilege.

\section{Masculinity, Fieldwork and Qualitative Research}

In contrast to the wealth of work exploring the theories and practice of feminist methodologies (Oakley, 1981; Finch, 1984; Ramazanoglu and Holland, 2002; Letherby, 2007), the methodological implications of researching men and their gender identities has until relatively recently been seldom addressed. Indeed, it has been suggested that 'in men researching men, the shared gendered experiences and assumptions about masculinity may be left unexamined' (Pini and Pease, 2013: 9). Yet, alongside the emergence of a now sizable corpus of literature addressing the critical study of men and masculinities (for example, see Connell, 2005; Kimmel, 2008; Aboim, 2012; Thurnell-Read and Casey, 2014; Ward 2015), there has been in recent years a greater willingness to reflect on the methodological challenges faced when researching men about their lives and their gendered identities. In spite of these advances in the conceptualisation of the social construction of masculinity and the diversity of ways in which masculinities become manifest, certain entrenched methodological problems have been noted when researching men about their gender identity. In relation to research on intimate, personal or sensitive topics, it has been suggested that men are difficult to recruit (Butera, 2006), and that of those who do participate in research there is a tendency towards nondisclosure of emotions and feelings (Schwalbe and Wolkomir, 2001; Allen 2008). While some have suggested that male research participants can also be beneficiaries of feminist methodologies with, for example, Gatrell (2006) observing that male interviewees appeared to enjoy a rare opportunity to get things 'off their chest', older men, in particular, are said to associate masculinity with 'stoicism' which gives rise to a 'lack of communication about problems and sources of stress' (Calasanti, 2004: 309). As Sallee and Harris (2011: 411) observe, 'discussing gender issues with men is fraught with additional complications, as men are typically socialized to avoid discussions about gender and masculinities that extend beyond heterosexual sex, toughness, and other topics that are socially constructed as masculine'. This willingness of disclosure, or lack of such, 
may be constituted by their age and generation, class or ethnicity as they intersect with masculinity (Hearn, 2009; Flood, 2013).

Conducting social research with men on the topic of men and masculinity, then, is neither straightforward nor is it without the need for further understanding to be developed. The way men perform their masculinity, their behaviour and actions, and the settings they occupy can all be overt and fully recognised yet, once addressed directly by the researcher, become stifled and almost taboo. Further still, as the chapter outlines, there is a particular importance of the intersection of age and masculinity in relation to how the latter is manifest in fieldwork and how we go about making sense of it through qualitative research. While the manner in which adolescent boys and young men perform and construct their masculinity might be more vivid (Gough and Edwards, 1998; Nayak and Kehily, 1996; Allen, 2005; Kimmel, 2008; Ward 2014), older men might be seen to offer less spectacular, though perhaps more subtle, performances of masculinity by invoking themes of authority, experience, rationality and control (See Tarrant this volume). For example, in Pini's (2005: 208) research she found that participants 'performed masculinity in the interview process by positioning themselves as busy, powerful and important men' and by adopting a paternal and authoritative tone of address. Similarly, Schwalbe and Wolkomir (2001: 97) suggest that 'the desire to signify a masculine self may lead men to exaggerate rationality, autonomy, and control when giving accounts of their experiences'. Moreover, the gender of the researcher is of central importance. Just as Pini (2005) found her male interviewees responded to her specifically as a female researcher, we can see that male participants may perform their gender in different ways, and be more or less willing to offer intimate thoughts and feelings, depending on whether they speak to a male and female researcher (Padfield and Procter, 1996; Sallee and Harris, 2011).

Age and gender evidently influence the relationship between researcher and the researched and, in various ways, infuse the focus and form of fieldwork interactions and, as a result, the types of findings made. Indeed, the very nature of these interactions reveals important insights into the way in which gender is performed by participants. Hearn (2013: 29), for example, reflects that 'elites and senior managers are often used to being listened to, presenting themselves, speaking authoritatively, 
avoiding direct questions, adapting to different situations and speaking on behalf of their organization'. While, in one regard, this presents a specifically practical issue of how to 'get at' the real thoughts and feelings behind the public 'front' of masculine authority, another perspective is to see these moments of encounter between researcher and research participant as important moments which are in and of themselves an opportunity for 'identity work', as male participants actively present and perform their masculine identities to the researcher. As Allen (2005: 37) suggests, 'these performances are important data in themselves, providing an opportunity to study masculinities in the making'.

The nature of this performance of masculinity which takes place during the research encounter is interwoven with subjectivities and positionings related to age and, indeed, social class, sexuality and various other lines of social difference. Recent years have seen an increased willingness to address the nature of masculinity in old age (Calasanti, 2004; Tarrant 2013) and, in particular, how men's identities can change as they transition through the life course (Spector-Mersel, 2006). Moments in the life course such as marriage (Thurnell-Read, 2012), fatherhood (Henwood and Procter, 2003; Coltart and Henwood, 2012), retirement and grandfatherhood (Mann, Tarrant and Lesson, 2015) have all been shown to give rise to associated reflections on and changes in men's sense of masculine selfhood. As the next section will describe, having conducted research on men and masculinities with male research participants of various ages, it appears opportune to reflect on the intersection of gender and age and how it influences the nature of fieldwork interactions.

\section{Methodological Reflections}

In writing this chapter I reflect on my experiences of three different research projects, all of which involved fieldwork in settings which were dominated, both numerically and socially, by men. These are: the modest research project of masculine workplace identities in the fire service conducted between December 2003 and April 2004 mentioned in opening this chapter; my doctoral research on British premarital 
stag $^{1}$ tourism in Eastern Europe conducted over the course of a year spanning 2007 and 2008; and, most recently, a study of the consumer pressure group The Campaign for Real Ale (CAMRA) and associated sites, groups and individuals related to ale drinking and beer connoisseurship conducted between 2012 and 2014. For simplicity of reference, I will refer to these three research undertakings as the fire service project, the stag tourism project and the ale project respectively. While I discuss various empirical findings from these projects elsewhere (for example, see Thurnell-Read and Parker, 2008; Thurnell-Read, 2012; Thurnell-Read; 2015), in this chapter I will draw on all three research undertakings in making observations on my experiences of being a (young) male researcher engaged in researcher on (often, much older) men. The nature of the relationships established in the field, I argue, tell us both about methodological concerns of doing qualitative research but also are in themselves insights into how men interact and bond in such settings. While age and ageing were not specified topics of interest in any of the projects, here, with the benefit of hindsight, I reflect on the varying displays of masculinity enacted by participants who, across the three projects, ranged from eighteen years old to their late seventies.

In all three projects periods of participant-observation were conducted and formal and informal interviews took place. Across these studies, exploring issues relating to how men enact their identities as men and how these identities are relational and context contingent has been a central concern. However, for a number of reasons, masculinity and gender subjectivity were often topics that had been raised or approached obliquely. As indicated above, a relative consensus exists in regard to the lack of willingness for men to talk openly and directly about intimate issues. During the stag tourism fieldwork, for example, I at first felt more comfortable limiting the questions I asked participants to those relating to tourist motivation and experiences of the Polish city, Kraków, in which the research took place. However the subject of men, male behaviour, and what men 'want' from a stag tour was rarely absent from participants' responses. Indeed, in all three projects, many participants spoke of gender albeit in typically colloquial, yet often loaded, terms. Some

\footnotetext{
${ }^{1}$ The premarital 'stag' party or tour is equivalent of the American 'bachelor party' or Australian 'bucks night' where the groom marks the occasion of his coming marriage with a gathering of male friends typically involving heavy, and often ritualistic, alcohol consumption.
} 
participants in the ale research referred to themselves as 'old gits' drinking in 'old man's pubs' and were aware of the perception of CAMRA being 'very blokey' and 'a men's drinking club'. As such, gender, the gender identities of participants and the gender biases of the social setting were, in each case, an ever-present yet equivocal constituent of fieldwork and, specifically, the form, language and content of fieldwork relations.

There is a notable tendency for reflexivity to be something done after fieldwork, as a cathartic debriefing before moving on to new research. This chapter is, however, a rare opportunity to reflect not on a single research project but on a number of projects and, in being as such more longitudinal across my early research career, a reflection of my own development as a researcher as much as methodological problems faced in a specific instance of fieldwork. My reflections on my earlier projects now take on a different hue in light of my more recent work. They involve both acquiring skills and experiences as a researcher which, one would hope, better equip us to forge equitable and beneficial relationships with the participants who populate our research and, secondly, involve learning about oneself.

\section{'This guy knows!': Knowledge, Gender and Rapport}

Various authors have suggested that the way men perform social interaction, and the way men talk in particular, reveal a great deal about male identity and the social construction of masculinity (Goffman, 1977; Coates, 2003). For example, Hearn (1994: 63) posits that 'a different kind of knowledge concerns men-only talk or menonly situations, clubs, pubs, societies', while Flood (2013: 68) reflects that 'in my research with young heterosexual men, one of the most striking patterns has been the presence of homosocial storytelling'. In qualitative fieldwork involving periods of participant-observation, it is somewhat unavoidable that the researcher engages with this 'men talk' and, in one form or another, becomes part of it. Further, it involves assumptions made by both parties, with the researcher in particular needing to be mindful of the ways in which their talk and that offered to them in exchange is mediated by assumptions about the gender subjectivities of both parties (See Parker this volume). Rather than trivial asides, such turns of phrase as 'you know what I mean' are linguistic devices used to bond male interviewer-interviewee pairings and 
to establish, or at least work towards, a shared vision of the subject at hand (Scwalbe and Wolkomir, 2001).

This section will suggest that such exchanges offer important clues to the relationships of fieldwork and, further still, to the ways in which men 'do' communication and social interaction as a means of establishing and maintaining masculine identity positions. An emphasis on talk and storytelling as a medium of male interaction and homosocial bonding was present in all three projects. Further still, in each case conversations characteristically involved the performance of knowledge and know-how. This was illustrated during the stag tour project. Thus, having visited the city on a number of occasions before commencing the research, and making multiple trips during the year in which I conducted fieldwork, I was readily positioned as someone with knowledge of the city. Invariably once stag tour group members knew that I had spent considerable time in Kraków I would be asked 'so, where is best to drink then?'. While each of these moments raised issues of reactivity - should $\mathrm{I}$, in offering such advice, change the direction and nature of the group's activities and experience of the city - they also allowed me to enact a knowledgeable position with familiarity of the city's night life. The affirmation bestowed by enacting such knowledge (memorably the best man of one stag group loudly proclaiming to the rest of the group 'this guy knows the best places, follow him!') was seductive and I would hazard a guess that few researchers are immune to the pull of desiring acceptance and the temptation to perform in ways that appear to gather such affirmation from participants (See Delamont this volume).

While this reflects the wider importance of reciprocity involved in sharing travel anecdotes to interactions that take place in tourist settings (Murphy, 2001), it also tells us something about both the performance of masculine identity and the nature of fieldwork rapport. These interactions were evidently informed by expectation that, as a man in my mid-twenties at the time of conducting the research, I would be similarly intent upon a particular vision of the 'booze, birds and banter' associated with 'lad culture' involving access to copious amounts of alcohol, the presence of attractive women and an array of bawdy storytelling and name-calling (Benwell, 2004; Phipps and Young, 2015). Thus, positioning myself as a participant-observer to the stag group's performance of a particular vision of masculinity raised a number 
of issues relating to complicity, acceptance and my own emotional responses to a social context at times overwhelming in its adherence to laddish or 'blokey' masculinity (See Thurnell-Read, 2011b for a more detailed discussion).

However, it was in the ale research project that this performance of knowledge and expertise came to the fore. During the ale research, the performance of beer knowledge became a way of relating to research participants and of being taken seriously. I gained increasing amounts of knowledge about beer and, by being able to converse comfortably with more experienced beer aficionados on topics such as brewery processes, styles and tastes, and the latest pub and brewery openings and closures, I consciously sought to work upon my ability to 'act the part'. Ongoing participation in a particular cultural field might therefore put pressure on the researcher to stay relevant and 'cool' through attempts to 'keep up' with popular culture (Beer, 2009). Again, while at one level this represents a process of attuning yourself to the language and meanings particular to your specific field and setting which are common to most social research undertakings, it is also of itself an example of an implicitly gendered manner of social interaction. Indeed, taking ale appreciation and connoisseurship seriously involved many participants in a conscious and long-term pursuit of knowledge and skills in consuming and talking about real ale (Thurnell-Read, 2015).

While within the setting considerable status was attached to being knowledgeable about beer, and being able to position oneself as a consummate 'beer geek', I learnt in time that such talk was as much about bonding as it was about the performance of status. For example, during interviews with key student ale society members, this sharing of information was invoked as an example of how welcoming and caring the society was to new members. Advising novice society members on choices of drinks and also, in the words of one former society president, 'just spending time chatting with them if, you know, they're a bit shy or unsure', was cast as openness, responsibility and inclusivity. On returning to field notes made across all three research undertakings, this near ritualistic performance of knowledge and know-how strikes me as being particularly gendered. While such exchanges of 'know-how' are part of establishing rapport they are also vitally indicative of the gendered nature of the social contexts in which I conducted my research. As Flood, (2013: 69) points 
out, as a male researcher, drawing on one's own 'familiarity with and embeddedness in masculinity and borrow from the norms of culturally approved male-to-male relationships' can help to facilitate fieldwork access and rapport but it can also raise tricky questions relating to complicity in offensive behaviour.

\section{'My Son's About Your Age, He's at Uni too': Age, Generation and Masculinity in Fieldwork}

As a researcher, the intersection of age and gender in the presentation of my own identity fed into the fieldwork experience in a number of ways. As I have progressed through my early research career, so to have the status and position commanded in relation to the field changed. During research with the local fire service undertaken whilst still an undergraduate student, my inexperience both as a researcher and relative to the profession resulted in me adopting an entirely 'novice' position. In contrast, the stag research involved participating with groups more or less my own age within the setting of the leisure spaces of the Kraków city centre, while the ale research involved participants characteristically much older or, in the case of members of a university student ale society who were typically in their late teens or very early twenties, considerably younger than myself at the time of research. While it would be reductive to over-attribute the differences in my experiences of conducting these studies to the variations in my age relative to that of my participants, there is considerable scope to seek to understand how fieldwork rapport and researcher-participant relationships are shaped by inter-generational and intragenerational affinities and mutuality. Fieldwork interactions may thus be influenced by age-specific expectations of gender and life experience. In particular, key life events such as entry into employment, marriage, parenthood and retirement may draw boundaries of (dis)identification amongst the researcher and participants. For example, one stag research participant observed 'this will be you soon' and 'you've got all this to look forward to' in relation to his description of his late twenties as involving several stag weekends every summer as a procession of his cohort of friends all married in their late twenties. As noted at the start of the chapter, the firefighter in his mid-thirties who wished he 'was young, free and single again' did so based on his reading of myself as fulfilling a role tied to prescriptive notions of youth 
and masculinity that associate adolescence with freedom from burdens and responsibility (Kimmel, 2008).

The larger age difference between me and the majority of participants in the ale research project meant that both during fieldwork and in many interviews my relative youth appeared to lend a leitmotif of paternalism to the relationships I established. Indeed, in some instances this perhaps involved me being interpreted as being younger than I am and, on more than one occasions, for being a student 'writing an essay about CAMRA' and, in one conversation at the AGM held in Norwich in April 2013 was told that 'my son's about your age, he's at uni too'. Such moments of misrecognition present a practical issue of how best, if at all, to correct participants by restating that I was not a student but a university lecturer and that my research is not an 'essay' but an ongoing research project findings from which are likely to appear in academic articles and publications. More significantly, they also indicate a preference for the type of relationships to be formed in the field, in a similar vein to the observation made by Bartholomaeus and Tarrant (2015: 13) relating to how older men can sustain the performance of masculinity in that 'their gender, age, and class enable them access to the role of wise "sage"".

\section{Feeling in Place and Embodying the Field}

So far my reflections have to some extent repeated a tendency apparent in existing literature on research that focuses on men and gender in its emphasis on talk and dialogue-based interactions between researcher and research participants. However, in this final section I wish to expand these observations to include the more embodied elements of fieldwork and how these too are influenced by the relative age and gender, as they intersect, of both myself and my participants. I therefore recognise in my own research encounters Flood's (2013: 72) acknowledgment that he has 'been conscious of 'performing' masculinities, through speech, dress, body language and demeanour'. By focusing on embodiment as well as speech it is possible to tap into a wider sense of fieldwork experience as sensed and felt and acknowledge, as Coffey (1998: 59) does, that 'our bodies and the bodies of others are central to the practical accomplishment of fieldwork'. As explored above, whilst engaging in fieldwork interactions I was required to, at least to 
some extent, perform my role as researcher in a manner appropriate to both my age and gender in order to 'fit in' with my various research settings. Thus, it is through the body that feelings of fitting in or feeling 'out of place' are felt and experienced (For more details see Thurnell-Read 2011b).

Given these reflections, and the greater recognition of the importance of the sensory to fieldwork (Pink, 2013), we must also acknowledge that the sense of being embodied in the field are important indicators both of researcher subjectivity and interpersonal relations in the field. While textual renditions of dialogue provide more overt and bounded examples of how interactions between the researcher and research participants are subject to differences in terms of gender, age, authority and power, the body is also an important 'tool' with which the researcher senses the field and, in doing so, generates knowledge and understanding. Thus, reflecting on the embodied aspects of fieldwork remind us of what Stephens and Delamont (2006: 321) refer to as the 'relative importance of body and of mind in ethnography, about the levels of physical and mental competence needed to study an energetic physical activity'. As such, we can view the bodily feelings and emotions of researchers as a source of information about feelings of difference and otherness (Low, 2015).

As an organisation, CAMRA is acutely aware of the significant skew in the age distribution of its membership. Committed members, those who attend local branch meetings, organise and staff beer festivals and, in particular, those who get involved with the internal politics of via attendance of the AGM and other organisational events, are predominantly older. While my gender and subcultural capital in being able to participant in conversations based on quite detailed knowledge of the British beer 'scene' allowed me to fit in, as a result of my age my presence at many such occasions was at times conspicuous. This is not to say that my presence was unwanted, indeed, on many occasions I recall CAMRA members going out of their way to make me welcome because of my relative youth. Noting Low's (2015) recent reflection of using sensory 'walkabout' methods to investigate the embodied experiences of ethnic enclaves of post-colonial cities, my own research settings have been marked by the gendering of social space. Thus, while the fire station was evidently considered to be a male place by participants, the stag tour groups were, by definition, homosocial spaces where any female participants remained exclusively 
in supporting roles of pub crawl guide or pub waitress. More complex, perhaps, the various real ale pubs and beer festivals visited during the ale research were also highly gendered and, as noted, aged. Having attended a number of beer festivals (typically taking place in exhibition halls, civic buildings, rugby club function rooms or temporarily constructed marquees) both as customer and as volunteer staff as part of the research, I came to realise how comfortable I felt in the familiar setting. On attending a local beer festival accompanied by my wife, however, I was interested to discuss with her how struck she was by the characteristic smells of spilt ale, body odour and 'pub grub' such as pasties and roast pork batches simmering under heat lamps and that these senses translated into feelings of discomfort and unease.

On reflection, then, my own embodied comfort in the setting was, it appeared, bred both of familiarity and of the privilege with which I could feel 'in place' in a very male dominated social space. Further still, leisure spaces such as these beer festivals are almost exclusively white (Spracklen, 2013). Something I have come to recognise and acknowledge is that my ability to conduct fieldwork in such settings, being as they are male orientated drinking spaces, is based on the privilege of white male embodiment (Dyer, 1997) that means I do not feel out of place, or 'at risk' (Lee, 1997), in such spaces.

One implication for reflecting on the knowledge that qualitative research yields is that while narrative form or discursive content of qualitative interviews might remain dominant, the affective, sensory elements of being 'in the field' are and will retain their epistemological value. There is then, a strong sense that participatory fieldwork ought to allow for such insights as researchers acquisition of knowledge and talk about the fieldwork scene as well as a knowledge of how that scene is actually embodied (Stephens and Delamont, 2006). The research process ought, therefore, to prompt critical reflection on the researcher's own gendered selfhood and gender performance (Hearn, 1994: 63; Sallee and Harris, 2011) not just in terms of conversational interaction, but also in a deeper more embodied sense of feeling oneself as a gendered, aged and ethnic subject being. Indeed, during all three research projects it was through contemplating the emotions and bodily feelings of fieldwork that I came close to what Pillow (2003: 181) suggests is 'a form of selfreflexivity as confession [which] often yields a catharsis of self-awareness for the 
researcher'. While I have not wished to fall into the 'fables' and 'minimelodramas' so common in 'confessional tales' of the hardship of fieldwork (Van Maanen, 2011), I have sought to demonstrate the value of seeing reflection upon one's research experiences as a periodic task.

\section{Lessons Learned}

- Reflections on the experiences of conducting qualitative fieldwork are an important both in their ability to illustrate how the researcher's personal and professional self-identity develops over time and, in and of themselves, in identifying key insights into the field of research.

- While extant literature emphasises issues of non-disclosure amongst male research participants, rapport is often established along gender specific lines through the enactment of site specific knowledge and sharing of 'know-how'.

- Masculinity and age intersect for both the researcher and the research participants during the process of fieldwork interaction and can involve both the researcher and the research subject performing gender.

- While discursive interactions offer clear illustrations of the interplay of researcher and research participant subjectivities, the senses and feelings by which the research 'feels' the field are also significant components of the research experience and are as such worthy of reflexive scrutiny.

\section{Conclusion}

In this chapter, I have sought to reflect on my experiences of conducting research in male dominated social spaces as a means of exploring how the work of fieldwork involves interpersonal relational work, embodied work and the work of critical selfreflexivity (Coffey, 1998). Specifically, the chapter has addressed how the gender and age, amongst other differences, of myself as research and the participants they interact with do unavoidably influence the form and function of fieldwork relationships. In all my research undertakings a certain rapport based on shared gender was evident and this was, further still, accentuated by my ability to 'fit in' and be accepted in my own performance of context specific masculinity (Jefferson, 
2002). This privilege, and it should be clearly named as such, has meant that being a young, middle-class, white, male researcher gave me access to particular settings, a particular ease of interaction and a freedom from worry about other troubles concerning fitting in that would not be so readily available to others.

However, the chapter has also sought to make observations on the importance of age in its intersection with gender identity. This has meant that the interactions I have had with research participants might have been informed by our genders, but also by our interpretations of each other's ages. Rapport is itself a rather amorphous concept and while a text-book definition might indicate candid self-disclosure as an indication of rapport being established between the researcher and a participants, I have implied here that rapport can take many forms and, in the male dominated social settings as discussed above, the exchange of knowledge and 'know-how' or an embodied feeling of being 'in place' are nonetheless important measures of the relationships established during fieldwork. Based on these experiences, I wish to avoid reinstating a blunt divide between insider and outsider roles and status. Rather, in each research setting I have experienced moments of connection, friendship and rapport alongside feelings, often deeply felt, of alienation and, on occasions, disgust and dissonance.

Additionally, I have attempted to keep in mind that for many of us our identity as researcher, and the practices involved in our research, can be seen as 'careers' in a positive sense of personal and professional growth. In this chapter, having reflected not on an isolated project but allowed myself the luxury of reflecting, admittedly rather loosely, across a number of undertakings I can see how my own identity as a researcher has evolved across research projects that are by turns similar and different. My gender, as well as my age, has been important in directing me to the topics of study I have chosen. So too has my engagement in research focusing on male behaviour and identity allowed me opportunities to learn about and reflect on my own masculinity which I value both in terms of academic and methodological interests as a practitioner of qualitative social research and, in a wider sense, as means of better understanding my own place in the world.

\section{Bibliography:}


Aboim, S. (2012). Plural Masculinities: The remaking of the self in private life. Farnham: Ashgate.

Allen, L. (2005). Managing masculinity: Young men's identity work in focus groups. Qualitative Research, 5(1), 35-57.

Allen, L. (2008). “Managing Masculinity: Young Men's Identity Work in Focus Groups." Qualitative Research, 5(1): 35- 57.

Bartholomaeus, C. and Tarrant, A. (2015). Masculinities at the Margins of "Middle Adulthood" What a Consideration of Young Age and Old Age Offers Masculinities Theorizing. Men and Masculinities, 1097184X15588592.

Beer, D. (2009). Can you dig it? Some reflections on the sociological problems associated with being uncool. Sociology, 43(6), 1151-1162.

Benwell, B. (2004). Ironic discourse evasive masculinity in men's lifestyle magazines. Men and Masculinities, 7(1), 3-21.

Butera, K. J. (2006). Manhunt The Challenge of Enticing Men to Participate in a Study on Friendship. Qualitative inquiry, 12(6), 1262-1282.

Calasanti, T. (2004). Feminist gerontology and old men. The Journals of Gerontology Series B: Psychological Sciences and Social Sciences, 59(6), S305-S314.

Clifford, G. (1973). The Interpretation of Cultures. New York: Basic.

Coates, J. (2003). Men Talk: Stories in the making of masculinities. Oxford: Blackwell.

Coffey, A. (1999). The Ethnographic Self: Fieldwork and the representation of identity. London: Sage. 
Coltart, C. and Henwood, K. (2012). On paternal subjectivity: A qualitative longitudinal and psychosocial case analysis of men's classed positions and transitions to first-time fatherhood. Qualitative Research, 12(1), 35-52.

Connell, R. (2005). Masculinities ( ${ }^{\text {nd }}$ edition). Cambridge: Polity Press.

Dyer, R. (1997). White. London: Routledge.

Finch, J. (1984). It's great to have someone to talk to: The ethics and politics of interviewing women. In C. Bell and H. Roberts (Eds.), Social Researching: Politics, Problems, Practice. London: Routledge.

Flood, M. (2013). 'Negotiating Gender In Men's Research Among Men' in Pini, B. and Pease, B. (eds) Men, Masculinities and Methodologies. London: Palgrave Macmillan.

Gatrell, C. (2006) Interviewing Fathers: Feminist Dilemmas in Fieldwork, Journal of Gender Studies, 15:3, 237-251, DOI: 10.1080/09589230600862059

Goffman, E. (1977). The Arrangement between the Sexes. Theory and Society, 4, 301-331.

Gough, B. and Edwards, G. (1998). The beer talking: Four lads, a carry out and the reproduction of masculinities. The Sociological Review, 46(3), 409-455.

Hammersley, M. and Atkinson, P. (2007). Ethnography: Principles in practice. London: Routledge.

Hearn, J. (1994). Research in men and masculinities: some sociological issues and possibilities. The Australian and New Zealand Journal of Sociology, 30(1), 47-70.

Hearn, J. (2009). From older men to boys: Masculinity theory and the life course(s). NORMA: The Nordic Journal of Masculinity Studies, 2(2): 79-84. 
Hearn, J. (2013). 'Methods and Methodologies in Critical Studies on Men and Masculinities' in Pini, B. and Pease, B. (eds) Men, Masculinities and Methodologies. London: Palgrave Macmillan.

Henwood, K. and Procter, J. (2003) 'The "good father": reading men's accounts of paternal involvement during the transition to first-time fatherhood', British Journal of Social Psychology, vol. 42, no. 3, pp. 337-356.

Jefferson, T. (2002). Subordinating hegemonic masculinity. Theoretical Criminology, $6(1), 63-88$.

Kimmel, M. (2008). Guyland: The Perilous World Where Boys Become Men: Understanding the Critical Years between 16 and 26. New York: Harper Collins.

Lee, D. (1997). Interviewing men: vulnerabilities and dilemmas. In Women's Studies International Forum (Vol. 20, No. 4, pp. 553-564). Pergamon.

Leontowitch, M. (2012). Interviewing Older Men. In Leontowitsch, M. (ed.) Researching Later Life and Ageing: Expanding Qualitative Research. Basingstoke: Palgrave Macmillan. 1-6.

Letherby, G. (2007). Feminist Research in Theory and Practice. Maidenhead: McGraw-Hill.

Low, K. E. (2015). The sensuous city: Sensory methodologies in urban ethnographic research. Ethnography, 16(3), 295-312.

Mann, R., Tarrant, A., and Leeson, G. W. (2015). Grandfatherhood: Shifting Masculinities in Later Life. Sociology, 0038038515572586.

Murphy, L. (2001). Exploring social interactions of backpackers. Annals of Tourism Research, 28(1), 50-67. 
Nayak, A., and M. J. Kehily. (1996). "Playing it straight: Masculinities, homophobias and schooling." Journal of Gender Studies. 5:211-30.

Oakley, A. (1981) Subject Woman. London: Martin Robertson.

Padfield, M. and Procter, I. (1996). The effect of interviewer's gender on the interviewing process: A comparative enquiry. Sociology, 30(2), 355-366.

Phipps, A. and Young, I. (2015). Neoliberalisation and 'Lad Cultures' in Higher Education. Sociology, 49(2), 305-322.

Pillow, W. (2003). Confession, catharsis, or cure? Rethinking the uses of reflexivity as methodological power in qualitative research. International Journal of Qualitative Studies in Education, 16(2), 175-196.

Pini, B. (2005). Interviewing men Gender and the collection and interpretation of qualitative data. Journal of Sociology, 41(2), 201-216.

Pini, B. and Pease, B. (2013). 'Gendering Methodologies in the Study of Men and Masculinities' in Pini, B. and Pease, B. (eds) Men, Masculinities and Methodologies. London: Palgrave Macmillan.

Pink, S. (2013). Doing Visual Ethnography. Oxford: Sage.

Ramazanoglu, C. and Holland, J. (2002). Feminist Methodology Challenges and Choices. London : SAGE.

Robb, M (2004) Exploring Fatherhood: Masculinity and Intersubjectivity In The Research Process, Journal of Social Work Practice: Psychotherapeutic Approaches in Health, Welfare and the Community, 18:3, 395-406, DOI: $10.1080 / 0265053042000314456$

Sallee, M. W., \& Harris, F. (2011). Gender performance in qualitative studies of masculinities. Qualitative research, 11(4), 409-429. 
Schrock, D. and Schwalbe, M. (2009) Men, Masculinity and Manhood Arts. Annual Review of Sociology 35, pp. 377-395.

Schwalbe, M., and Wolkomir, M. (2001). The masculine self as problem and resource in interview studies of men. Men and masculinities, 4(1), 90-103.

Spector-Mersel, G. (2006). Never-aging stories: Western hegemonic masculinity scripts. Journal of Gender Studies, 15(1), 67-82.

Spracklen, K. (2013). Whiteness and Leisure. London: Palgrave Macmillan.

Stephens, N., and Delamont, S. (2006). Balancing the Berimbau Embodied Ethnographic Understanding. Qualitative Inquiry, 12(2), 316-339.

Tarrant, A. (2013). Grandfathering as Spatio-temporal Practice: Conceptualizing Performances of Ageing Masculinities in Contemporary Familial Carescapes, Social and Cultural Geography. 14(2): 192-210.

Thurnell-Read, T. (2011a). Off the leash and out of control: masculinities and embodiment in Eastern European stag tourism. Sociology, 45(6), 977-991.

Thurnell-Read, T. (2011b). 'Common-sense' research: Senses, emotions and embodiment in researching stag tourism in Eastern Europe. Methodological Innovations Online, 6(3), 39-49.

Thurnell-Read, T. (2012). What Happens on Tour The Premarital Stag Tour, Homosocial Bonding, and Male Friendship. Men and Masculinities, 15(3), 249-270.

Thurnell-Read, T. (2014). Craft, tangibility and affect at work in the microbrewery. Emotion, Space and Society, 13, 46-54.

Thurnell-Read, T. (2015). 'Real Ale' Enthusiasts, Serious Leisure and the Costs of Getting 'Too Serious' About Beer. Leisure Sciences, (ahead-of-print), 1-17. 
Thurnell-Read, T. and Casey, M. (Eds) (2014) Men, Masculinities, Travel and Tourism. Basingstoke: Palgrave MacMillan.

Thurnell-Read, T., and Parker, A. (2008). Men, masculinities and firefighting: Occupational identity, shop-floor culture and organisational change. Emotion, Space and Society, 1(2), 127-134.

Townsend, N. (1999). Fatherhoods and Fieldwork Intersections between Personal and Theoretical Positions. Men and Masculinities, 2(1), 87-97.

Van Maanen, J. (2011). Tales of the Field: On writing ethnography. Chicago: University of Chicago Press.

Walby, K. (2010). Interviews as encounters: issues of sexuality and reflexivity when men interview men about commercial same sex relations. Qualitative Research, 10(6), 639-657.

Ward, M. R. M. (2014). "'I'm a Geek I am': academic achievement and the performance of a studious working-class masculinity." Gender \& Education, 26(7): 709-725.

Ward, M. R. M. (2015). From Labouring to Learning, Working-Class Masculinities, Education and De-Industrialization. Basingstoke: Palgrave Macmillan.

West, C. and Zimmerman, D. H. (1987). Doing gender. Gender and Society, 1(2), 125-151. 